\title{
A Validated RP-HPLC Method for Quantitative Determination of Related Impurities of Cholic Acid Bulk Drugs
}

\author{
Zhaojun Sheng $^{1 *} \uparrow$, Ruhan $\mathrm{Ye}^{1,2} \uparrow$, Siyuan $\mathrm{Ge}^{1}$, Chenggang Wang ${ }^{2}$, Xuetao $\mathrm{Xu}^{1}$, \\ Guangwen Zhang ${ }^{2}$ and Ping Luo ${ }^{2}$ \\ ${ }^{1}$ School of Chemical and Environmental Engineering, Wuyi University, Jiangmen 529020, China \\ ${ }^{2}$ New Fortune Environmental Protection Co. Ltd. Yamen Jiangmen, Jiangmen 529152, China
}

Received: 09 February 2017; accepted: 17 April 2017

\begin{abstract}
An efficient and convenient reversed-phase high-performance liquid chromatography method has been developed and validated for the quantitative determination of cholic acid bulk drugs and their related impurities. Chromatographic separation was performed on a YMC-Pack ODS-AQ column $(250 \mathrm{~mm} \times 4.6 \mathrm{~mm}, \mathrm{~S}-5 \mu \mathrm{m}, 12 \mathrm{~nm})$, and the mobile phase consisted of acetonitrile, methanol, and diluted formic acid solution $(\mathrm{pH} 2.5)$ at a flow rate of $1.0 \mathrm{~mL} / \mathrm{min}$. The analytes were monitored using a refractive index detector at $30{ }^{\circ} \mathrm{C}$, and the column temperature was $30{ }^{\circ} \mathrm{C}$. Under the above chromatographic conditions, the method has good specificity and specified impurities can be effectively separated. The proposed method is found to have linearity in the $2.0-80.0 \mu \mathrm{g} / \mathrm{mL}$ concentration range with correlation coefficients of not less than 0.9999 . The compounds analyzed in the solutions are stable for at least 7 days, and spike recoveries for all specified impurities range from $91.3 \%$ to $109.3 \%$ with relative standard deviations (RSDs) not more than $7.3 \%$. The limit of detection and the limit of quantification for the analytes are $0.060 \mu \mathrm{g} / \mathrm{mL}$ and $2.0 \mu \mathrm{g} / \mathrm{mL}$, respectively. The proposed method can be applied in the quality control assay of cholic acid bulk drugs, with the advantages of simplicity, accuracy, robustness, good selectivity, and high sensitivity.
\end{abstract}

Keywords: Reversed-phase HPLC, quality control, bulk drugs, cholic acid

\section{Introduction}

Cholic acid (CA), also known as $3 \alpha, 7 \alpha, 12 \alpha$-trihydroxy- $5 \beta$ cholan-24-oic acid, along with chenodeoxycholic acid (CDCA), is one of the two primary bile acids produced by the liver, where it is synthesized from cholesterol [1-3]. In addition to primary bile acids, secondary bile acids (ursodeoxycholic acid [UDCA], deoxycholic acid [DCA], and lithocholic acid [LC]) are generated by the intestinal bacteria from primary bile acids [2-4]. Bile acids have multiple physiological functions, for example, acting as emulsifiers of dietary lipids, enhancing tryptic cleavage of dietary proteins, and having antibacterial effects $[1,4]$. The structures of various bile acids are depicted in Figure 1.

$\mathrm{CA}$ is manufactured using bovine and ovine bile as the source material [5] and is a by-product of the meat processing industry. CA is mainly used for the preparation of Chinese patent medicines such as artificial Calculus Bovis, Bovis Calculus Sativus, Qingkailing oral liquid, and Qingkailing injection, which have detoxification, anti-inflammatory, and antiviral properties, and are used clinically for the treatment of fever, coma, stroke, sore throat, and sore tongue [6]. In China, most commercial cholic acid is extracted with methanol, resulting in cholic acid methyl ester (CAME, Figure 1) as a residual impurity in cholic acid bulk drugs. Apart from the ester impurity, the potential impurities in the raw material include other bile acids, such as CDCA and DCA. Thus, CAME, CDCA, and DCA are considered as the main impurities in cholic acid bulk drugs. Although several papers have reported the analysis of various bile acids and their related impurities [7-11], there are few reports on the high-performance liquid chromatography (HPLC) method for the separation and quantitative determination of the related impurities of CA bulk drugs, especially the ester impurity. For example, the analysis of

\footnotetext{
* Author for correspondence: wyuchemszj@126.com
}

$\dagger$ These authors contributed equally to this work. related impurities in UDCA has been reported in the European Pharmacopoeia 7.0 [12]. Although the structure of UDCA is very similar to that of $\mathrm{CA}$, the reported method has been proved to be unsuitable for the determination of $\mathrm{CA}$ bulk drugs containing the ester impurity. However, CAME is the main impurity in CA bulk drugs and greatly influences its quality. Thus, there is a great need to develop an efficient HPLC analytical method for the separation and determination of related impurities to control the quality of CA bulk drugs. In this report, we present a reversed-phase (RP)HPLC method for quantitative determination of the impurities in CA bulk drugs by refractive index detection. The method is shown to be highly selective, linear, accurate, precise, sensitive, and robust.

\section{Experimental}

Chemicals and materials. All reagents were of analytical reagent grade, unless stated otherwise. Deionized water was obtained by the Milli-Q system (Millipore, USA). HPLC-grade acetonitrile and methanol were from Oceanpak Alexative Chemical (Gothenburg, Sweden). Formic acid was from Guangzhou Chemical Reagent Factory (Guangzhou, China). CA bulk drugs were from a local manufacturing company in Guangzhou, China. CA reference standard (HPLC purity: 100\%) and its related substance CDCA (HPLC purity: 99.2\%) were from China National Institutes for Food and Drug Control (Beijing, China). CAME (NMR purity: 99.76\%) was synthesized and quantitatively analyzed by the China National Analytical Center (Guangzhou, China). DCA (HPLC purity: 99\%) was from Sigma-Aldrich (Shanghai, China).

Instrumentation and HPLC analysis. HPLC analysis was performed on an Agilent 1260 HPLC system (Agilent Technologies, Palo Alto, CA, USA), equipped with a quaternary gradient pump, autosampler, vacuum degasser, and

This is an open-access article distributed under the terms of the Creative Commons Attribution-NonCommercial 4.0 International License (https://creativecommons.org/licenses/by-nc/4.0/), which permits unrestricted use, distribution, and reproduction in any medium for non-commercial purposes, provided the original author and source are credited, a link to the CC License is provided, and changes - if any - are indicated. 
<smiles>C[C@H](CCC(=O)O)[C@H]1CC[C@H]2[C@H]3[C@H](C[C@H](O)[C@]21C)[C@@]1(C)CC[C@H](O)C[C@@H]1C[C@H]3O</smiles>

Cholic acid (CA)

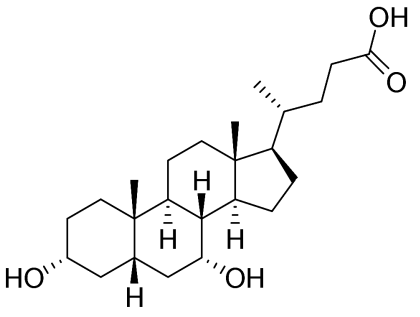

Chenodeoxycholic acid (CDCA)

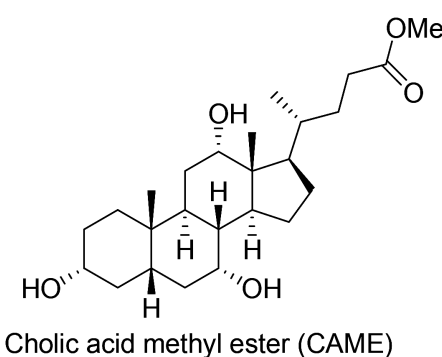

Cholic acid methyl ester (CAME)

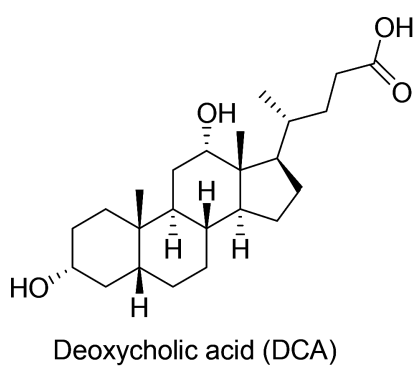

Deoxycholic acid (DCA)

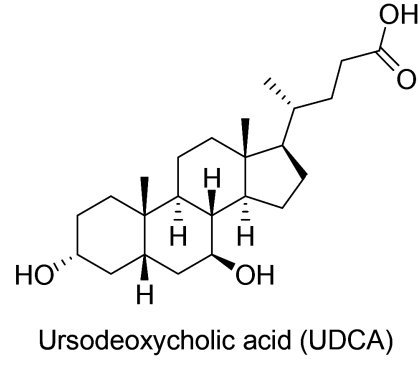

Figure 1. Chemical structures of various bile acids and CAME

refractive index detector at $30{ }^{\circ} \mathrm{C}$, using a YMC-Pack ODS-AQ $(\mathrm{C} 18,250 \mathrm{~mm} \times 4.6 \mathrm{~mm}$ I.D., $5 \mu \mathrm{m}$ dp; YMC, Kyoto, Japan $)$ column with a flow rate of $1.0 \mathrm{~mL} / \mathrm{min}$ and column temperature of $30{ }^{\circ} \mathrm{C}$. The injection volume was $50 \mu \mathrm{L}$ with needle wash. The mobile phase was a mixture of acetonitrile, methanol, and a dilute solution of formic acid in water at $\mathrm{pH} 2.5$ $(43: 17: 40, \mathrm{v} / \mathrm{v} / \mathrm{v})$. Data collection and integration were performed with Agilent Chemstation B.04.01 software. The assay of related impurities was calculated by CA external standard method with relative response factor (RRF), obtained by comparing the slopes of the calibration equations of $\mathrm{CA}$ and the related impurities.

Preparation of standard solutions and sample solutions. The standard solution of CA $(20 \mu \mathrm{g} / \mathrm{mL})$ and a sample solution of CA $(4 \mathrm{mg} / \mathrm{mL})$ were prepared using 60:40 (v/v) acetonitrilewater as solvent. The resolution solution of CA $(4 \mathrm{mg} / \mathrm{mL})$, CDCA $(40 \mu \mathrm{g} / \mathrm{mL})$, CAME $(40 \mu \mathrm{g} / \mathrm{mL})$, and DCA $(40 \mu \mathrm{g} / \mathrm{mL})$ was prepared in the same solvent.

Preparation of standard stock solutions for validation process. Stock solutions $(0.4 \mathrm{mg} / \mathrm{mL})$ of CA and related substances CDCA, CAME, and DCA were prepared in the same solvent and were further diluted to study linearity, accuracy, precision, the limit of detection (LOD), and the limit of quantification (LOQ).

\section{Results and Discussion}

Method development. Because of the low ultraviolet absorption of CA and its related impurities at 200-400 nm, a refractive index detector was chosen. Firstly, different stationary phases $\left(\mathrm{RP}-\mathrm{C}_{8}\right.$ and $\left.\mathrm{RP}-\mathrm{C}_{18}\right)$ and columns of different brands (Agilent, Alltima, Waters XBridge, and YMC) were evaluated to obtain good peak shape, symmetry, and resolution. $\mathrm{RP}_{-} \mathrm{C}_{8}$ showed high tailing factors for CDCA, CAME and DCA, while RP-C 18 gave lower tailing factors (less than 1.5), and was, therefore, chosen as the stationary phase. Compared with different brands of columns, the highest peak resolution, based on CA and its related impurities separation, was accomplished with the YMC-Pack ODS-AQ analytical column $(250 \mathrm{~mm} \times$ $4.6 \mathrm{~mm}, 5 \mu \mathrm{m})$.

Then, the analytes were eluted on a RP- $\mathrm{C}_{18}$ column with the same mobile phase used for UDCA reported in the European Pharmacopoeia 7.0 [12]. The result is shown in Figure 2a: this mobile phase $(\mathrm{MeCN}-\mathrm{MeOH}-$ phosphate buffer $=30: 40: 37)$ resolved CA, but not the impurities, CDCA and CAME. Moreover, in this method, the sample solution was prepared in a solvent mixture of $\mathrm{MeCN}-\mathrm{MeOH}-$ phosphate buffer, which led to the instability of the sample solution, especially under acidic conditions. For example, in the initial acidic degradation study of CA bulk drug, $17.1 \%$ of CA was degraded if the sample solution was prepared in the solvent mixture of $\mathrm{MeCN}-\mathrm{MeOH}-$ phosphate buffer. Then, the degraded and neutralized sample solution was kept for 6 days more; up to $83.9 \%$ of CA was degraded. However, under the same conditions, only $6.10 \%$ of CA was degraded if the sample solution was prepared in the solvent mixture of $\mathrm{MeCN}$ and $\mathrm{H}_{2} \mathrm{O}$, and no further degradation was detected. Hence, in order to avoid the instability of the sample solution, the samples were prepared in the solvent mixture of $\mathrm{MeCN}$ and $\mathrm{H}_{2} \mathrm{O}(60: 40)$.

Next, the composition of mobile phase was optimized through several trials. At the very beginning, the composition of the mobile phase $(\mathrm{MeCN}-\mathrm{MeOH}$-phosphate buffer = 30:40:37) in European Pharmacopoeia 7.0 was used as a reference; different proportions of $\mathrm{MeCN}, \mathrm{MeOH}$, and diluted formic acid solution ( $\mathrm{pH} 2.5)$ were tried. As shown in Table 1, the results demonstrate that the key to the method development is to resolve CAME and the other impurities. Increasing the proportion of acetonitrile and reducing that of methanol helped to separate the three impurities and shorten the whole run-time. In the trail 1, the peaks of CAME and DCA overlapped. In the trials 2 and 3, the two peaks did not separate completely as well. In the trials 4 and 5, the resolution of CDCA, CAME, and DCA met the requirements. Considering the resolution and efficiency, 43:17:40 (v/v/v) of MeCN-MeOH-diluted formic acid solution ( $\mathrm{pH}$ 2.5) was chosen as the mobile phase. A typical chromatogram of CA and its impurities obtained under the final conditions is depicted in Figure 2b. As shown in the chromatogram, the method is capable of separating CA and its impurities.

Method validation. The method developed was validated according to the guidelines [13-15], as described below, for the following parameters: system suitability test, specificity, linearity, accuracy, precision, LOD, LOQ, and robustness.

System suitability test. In a pharmacopoeia liquid chromatography analysis, system suitability test (SST) is suggested to check its separation quality. The SST was developed by single injection of the resolution solution and five replicate injections of the standard solution, both described in the experimental section. 

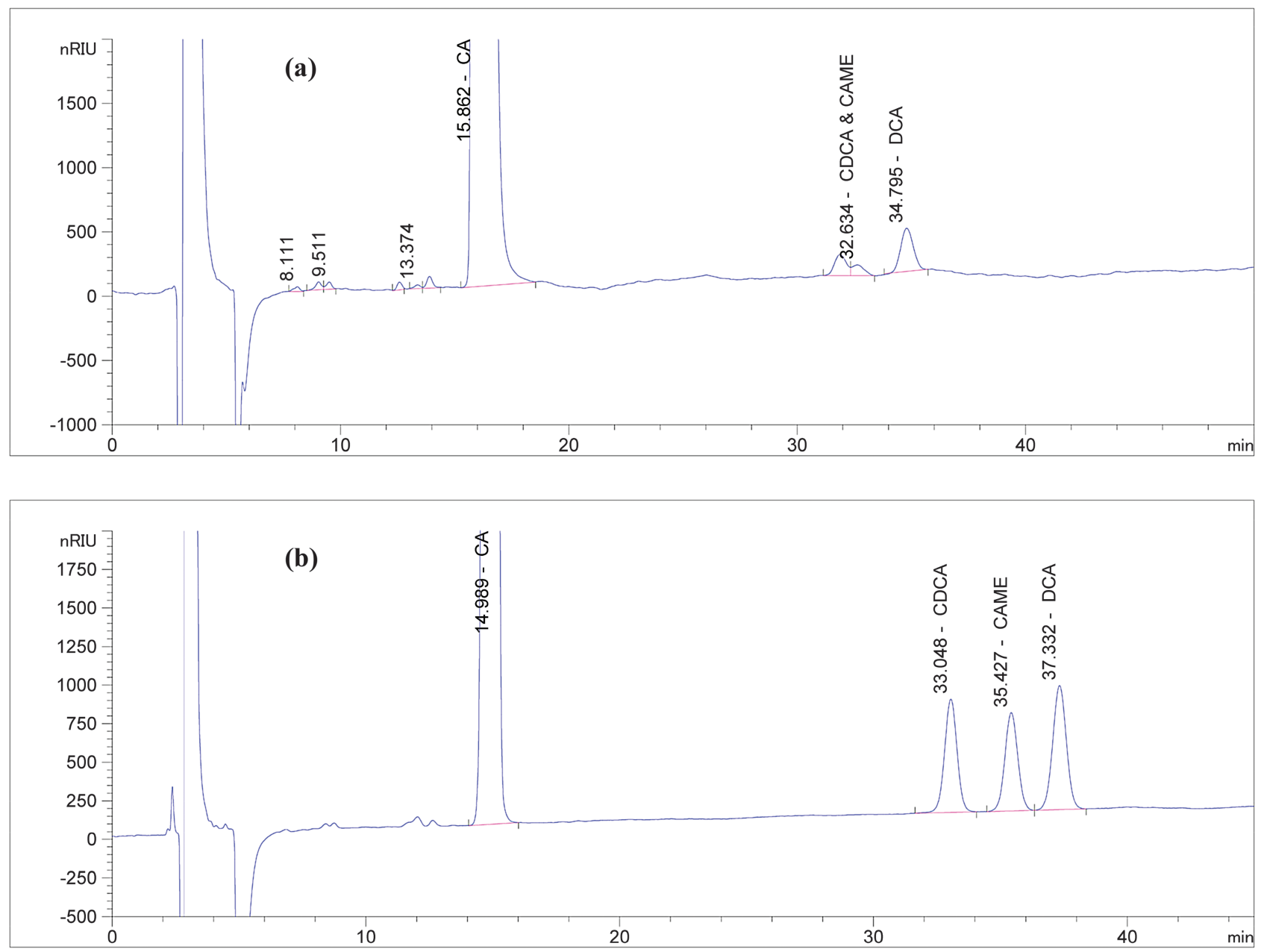

Figure 2. (a) Chromatogram of CA bulk drug by the method of the European Pharmacopoeia 7.0; (b) typical chromatogram of CA and its specified impurities obtained under the final conditions

Table 1. Optimization of mobile phase

\begin{tabular}{lcccc}
\hline Trial no. & $\begin{array}{c}\text { MeCN-MeOH-diluted formic } \\
\text { acid solution (pH 2.5) }\end{array}$ & $\begin{array}{c}\text { Retention time of } \\
\text { main peak (min) }\end{array}$ & Resolution \\
\cline { 2 - 5 } & $50: 15: 35$ & 9.4 & 3.97 & CAME and DCA \\
\hline & $47: 16: 37$ & 11.5 & 3.18 & 1.27 \\
3 & $45: 17: 38$ & 12.7 & 3.09 & 1.53 \\
4 & $43: 17: 40$ & 15.4 & 2.80 & 2.08 \\
5 & $39: 19: 42$ & 22.3 & 1.79 & 2.98 \\
\hline
\end{tabular}

The important SST parameters and the repeatability of all the validation items are shown in Table 2. The relative standard deviations (RSDs) of the CA peak area of standard and resolution solutions satisfy the acceptance criteria.

Specificity. The specificity was demonstrated by spiking the specified impurities and forced degradation studies. For all degradation studies, about $100 \mathrm{mg}$ of CA bulk drug was accurately weighed and prepared at a CA concentration of $4 \mathrm{mg} / \mathrm{mL}$ in $60: 40 \mathrm{v} / \mathrm{v} \mathrm{MeCN}-\mathrm{H}_{2} \mathrm{O}$. For acidic and alkaline degradation studies, CA was dissolved in $5 \mathrm{~mL}$ of $0.5 \mathrm{M} \mathrm{HCl}$, and $5 \mathrm{~mL}$ of $0.5 \mathrm{M} \mathrm{NaOH}$, respectively, and then the solutions were kept in a water bath at $98-100{ }^{\circ} \mathrm{C}$ for $5 \mathrm{~h}$. For oxidative

Table 2. System suitability parameters

\begin{tabular}{|c|c|c|c|c|c|c|c|c|c|c|c|c|}
\hline \multirow[t]{2}{*}{ Items } & \multirow{2}{*}{$\begin{array}{l}\text { RSDs of } \\
\text { CA peak } \\
\text { area }(\%)\end{array}$} & \multicolumn{3}{|c|}{ Resolution } & \multicolumn{4}{|c|}{ Tailing factor } & \multicolumn{4}{|c|}{ Number of theoretical plates } \\
\hline & & $\overline{\mathrm{CA}-\mathrm{CDCA}}$ & CDCA-CAME & $\overline{\text { CAME-DCA }}$ & $\mathrm{CA}$ & CDCA & CAME & $\mathrm{DCA}$ & $\mathrm{CA}$ & $\mathrm{CDCA}$ & CAME & $\overline{\mathrm{DCA}}$ \\
\hline Specificity & 1.0 & 26.46 & 2.86 & 1.97 & 1.04 & 0.98 & 1.00 & 1.02 & 12667 & 22589 & 23402 & 23663 \\
\hline Linearity & 0.9 & 26.53 & 2.93 & 1.93 & 1.01 & 1.03 & 1.02 & 1.00 & 12683 & 24438 & 24812 & 25343 \\
\hline Accuracy & 0.9 & 26.53 & 2.93 & 1.93 & 1.01 & 1.03 & 1.02 & 1.00 & 12683 & 24438 & 24812 & 25343 \\
\hline Repeatability & 0.9 & 26.53 & 2.93 & 1.93 & 1.01 & 1.03 & 1.02 & 1.00 & 12683 & 24438 & 24812 & 25343 \\
\hline Intermediate precision & 0.5 & 25.51 & 2.61 & 1.99 & 1.01 & 1.01 & 1.04 & 1.02 & 12689 & 22514 & 22918 & 23271 \\
\hline LOD & 0.9 & 26.53 & 2.93 & 1.93 & 1.01 & 1.03 & 1.02 & 1.00 & 12683 & 24438 & 24812 & 25343 \\
\hline LOQ & 0.9 & 26.53 & 2.93 & 1.93 & 1.01 & 1.03 & 1.02 & 1.00 & 12683 & 24438 & 24812 & 25343 \\
\hline Solution stability & $0.5-1.0$ & 25.51 & 2.61 & 1.93 & 1.01 & 1.01 & 1.04 & 1.02 & 12689 & 22514 & 22918 & 23271 \\
\hline Robustness & $0.3-2.3$ & 22.93 & 2.15 & 1.54 & 1.27 & 1.06 & 1.19 & 0.94 & 13114 & 21504 & 22389 & 22882 \\
\hline Limit & NMT 5.0 & NLT 1.5 & NLT 1.5 & NLT 1.5 & NMT 1.5 & NMT 1.5 & NMT 1.5 & NMT 1.5 & & & & \\
\hline
\end{tabular}


conditions, degradation was performed in 3\% hydrogen peroxide solution, kept in a water bath at $40{ }^{\circ} \mathrm{C}$ for $24 \mathrm{~h}$. To evaluate the influence of the reagents $(0.5 \mathrm{M} \mathrm{HCl}, 0.5 \mathrm{M}$ $\mathrm{NaOH}$, and $3 \% \mathrm{H}_{2} \mathrm{O}_{2}$ ), blank solutions of acidic, alkaline, and oxidative conditions were studied under the same conditions as the sample solutions. For the heat stress study, CA was placed in a hot-air oven maintained at $80{ }^{\circ} \mathrm{C}$ for 14 days. For the photodegradation study, CA was exposed as a thin layer in an illumination test chamber at $4500 \pm 500 \mathrm{Lx}$ for 14 days. Prior to HPLC analysis, acidic and alkaline samples were first neutralized by adding the appropriate amount of $0.5 \mathrm{M} \mathrm{NaOH}$ and $0.5 \mathrm{M} \mathrm{HCl}$, respectively, and then diluted with $60: 40 \mathrm{v} / \mathrm{v}$ $\mathrm{MeCN}-\mathrm{H}_{2} \mathrm{O}$.

The chromatogram of the resolution solution described in SST showed that the separation between CA and the specified impurities was acceptable. The results of degradation studies are shown in Table 3. In the case of acidic stress, $6.1 \%$ of degradation products were detected. The degradation products under other conditions represent $0.60 \%$ to $0.95 \%$. The results indicate that $\mathrm{CA}$ bulk drug is stable when exposed under these conditions, except for acidic conditions. A typical chromatogram of an acidic degradation study of CA is shown in Figure 3; it shows that the method is capable of separating all detected analytes including CA, specified impurities, and unknown impurities.

Linearity. Linearity was checked by analyzing CA and its related impurities in the $2.0-80.0 \mu \mathrm{g} / \mathrm{mL}$ concentration range. Solutions with six different concentrations (2.0, 4.0, 8.0, 20.0, 40.0, and $80.0 \mu \mathrm{g} / \mathrm{mL}$ ) were prepared, and each solution was injected twice. Peak areas of each compound were measured and used for quantification. Linear calibration plots $(y=a x+b)$ between the peak area $(y)$ and quantity $(x, \mu \mathrm{g} / \mathrm{mL})$ were investigated for each standard compound. Slope, intercept, correlation coefficient $(r)$, relative retention time (RRT), and relative response factor (RRF) were calculated. The results of the regression statistics for all the analytes (Table 4) indicate that the method is linear over the concentration range studied.
Table 4. Linear parameters of CA and its related substances

\begin{tabular}{lccccc}
\hline Analyte & Calibration equation & $r$ & $\begin{array}{c}\text { Linear range } \\
(\mu \mathrm{g} / \mathrm{mL})\end{array}$ & $\mathrm{RRT}^{a}$ & $\mathrm{RRF}^{b}$ \\
\hline CA & $y=554.07 x+144.63$ & 0.9999 & $2.00-79.96$ & 1.0 & 1.0 \\
CDCA & $y=522.24 x+85.91$ & 0.9999 & $2.00-79.99$ & 2.202 & 1.061 \\
CAME & $y=520.53 x+48.09$ & 0.9999 & $2.00-79.93$ & 2.372 & 1.064 \\
DCA & $y=548.96 x+1.45$ & 0.9999 & $2.00-79.99$ & 2.491 & 1.009 \\
& ${ }^{a}$ RRT: obtained by comparing the retention time of related substances \\
and CA. \\
${ }^{b}$ RRF: obtained by comparing the slope of calibration equation of CA \\
and its related substances. \\
\hline
\end{tabular}

Accuracy. The accuracy of the HPLC analysis was determined by spike recovery. Sample solutions were spiked with various amounts of CDCA, CAME, and DCA at concentrations of $2 \mu \mathrm{g} / \mathrm{mL}, 20 \mu \mathrm{g} / \mathrm{mL}$, and $80 \mu \mathrm{g} / \mathrm{mL}$. Three separate spiked solutions were prepared for each concentration. For comparison, a blank sample not spiked with related impurities was prepared and analyzed.

The results of this study are listed in Table 5. In the 2.0 $80.0 \mu \mathrm{g} / \mathrm{mL}$ concentration range, the recoveries of CDCA, CAME, and DCA were found to be $91.3-98.7 \%, 95.7-99.8 \%$, and $98.5-109.3 \%$, respectively. The data demonstrate that the established method is accurate

Precision. Precision was evaluated in terms of repeatability and intermediate precision. Repeatability was assessed using six separate sample solutions on the same equipment on the same day. The intermediate precision was calculated from six freshly prepared sample solutions at the same condition of repeatability on another day by another analyst; the RSD values were calculated from the peak areas of the impurities.

The repeatability RSDs of CDCA, CAME, DCA, and total impurities were $2.5 \%, 6.8 \%, 2.1 \%$, and $1.5 \%$, respectively. The intermediate precision RSDs of CDCA, CAME, DCA, and total impurities were $3.4 \%, 6.3 \%, 3.0 \%$, and $1.7 \%$, respectively. In all instances, RSD values were less than $15 \%$. The results are in accordance with acceptance criteria reported in the guideline issued

Table 3. Results of degradation studies

\begin{tabular}{|c|c|c|c|c|c|c|}
\hline \multirow{2}{*}{$\begin{array}{l}\text { Degradation } \\
\text { conditions }\end{array}$} & \multirow{2}{*}{$\begin{array}{l}\text { Purity of main } \\
\text { component }(\%)\end{array}$} & \multicolumn{3}{|c|}{ Amount of known impurities (\%) } & \multirow{2}{*}{$\begin{array}{l}\text { Amount of } \\
\text { impurities (\%) }\end{array}$} & \multirow{2}{*}{$\begin{array}{l}\text { Resolution of main peak } \\
\text { and its closest peak }\end{array}$} \\
\hline & & CDCA & CAME & DCA & & \\
\hline Blank & 99.35 & 0.17 & 0.08 & 0.36 & 0.67 & 5.55 \\
\hline Acidic & 93.59 & 0.16 & 0.07 & 0.36 & 6.10 & 4.04 \\
\hline Alkaline & 99.40 & 0.16 & ND & 0.36 & 0.60 & 4.34 \\
\hline Oxidative & 99.06 & 0.18 & 0.10 & 0.36 & 0.95 & 4.58 \\
\hline Heat & 99.15 & 0.16 & 0.09 & 0.35 & 0.85 & 5.12 \\
\hline photo & 99.31 & 0.18 & 0.08 & 0.36 & 0.69 & 6.20 \\
\hline
\end{tabular}

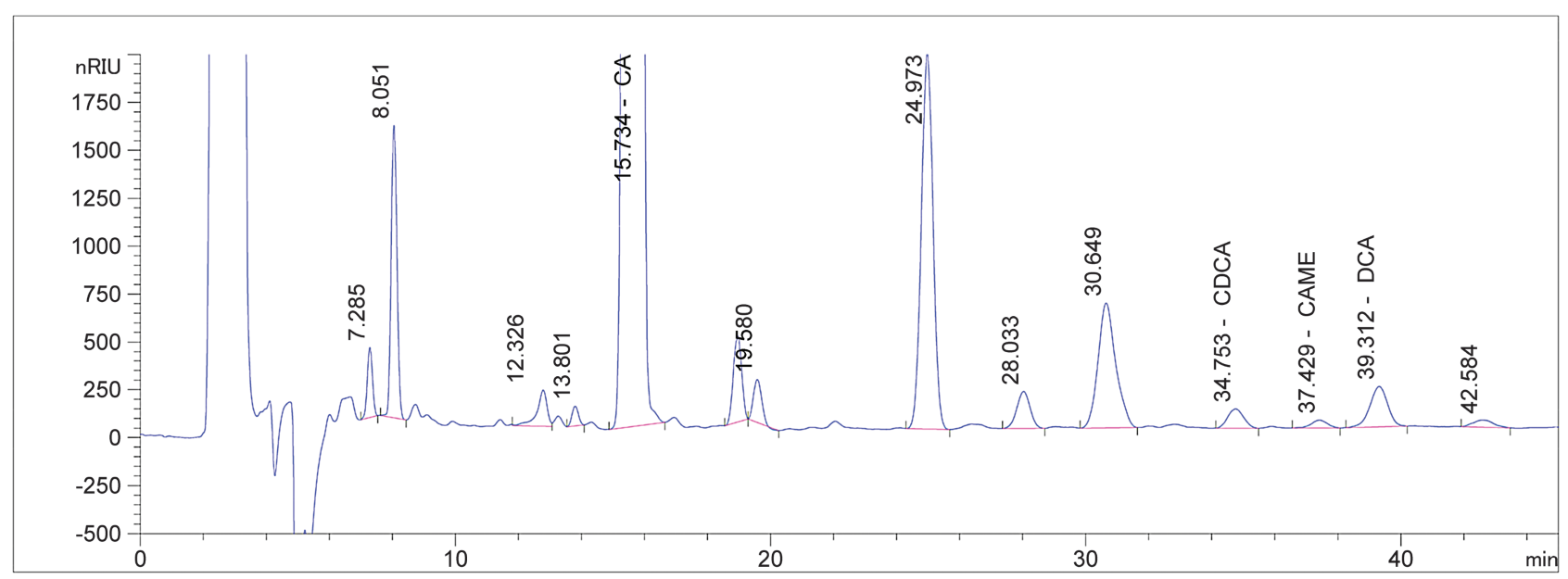

Figure 3. Typical chromatogram for acidic degradation study of CA bulk drug 
Table 5. Recovery of CA-related substances

\begin{tabular}{lccccc}
\hline Analyte & Added $(\mu \mathrm{g} / \mathrm{mL})$ & Found $(\mu \mathrm{g} / \mathrm{mL})$ & Recovery $(\%)$ & Mean recovery $(\%)$ & RSD $(\%)$ \\
\hline \multirow{2}{*}{ CDCA } & 2.00 & $1.69,1.82,1.96$ & $84.7,91.1,98.1$ & 91.3 & 7.3 \\
& 20.00 & $19.50,19.48,19.68$ & $97.5,97.4,98.4$ & 98.7 & 0.3 \\
& 79.99 & $78.60,79.05,79.14$ & $98.3,98.8,98.9$ & 95.7 & 0.6 \\
CAME & 2.00 & $1.81,1.88,2.05$ & $90.7,94.1,102.3$ & 99.8 & 6.2 \\
& 19.98 & $20.26,19.33,20.23$ & $101.4,96.8,101.3$ & 99.2 & 2.6 \\
& 79.93 & $78.97,79.56,79.31$ & $98.8,99.5,99.2$ & 109.3 & 0.4 \\
DCA & 2.00 & $2.21,2.24,2.10$ & $110.3,112.2,105.3$ & 98.5 & 3.3 \\
& 20.00 & $19.47,20.38,19.24$ & $97.4,101.9,96.2$ & 99.4 & 3.1 \\
& 79.99 & $78.93,79.19,80.45$ & $98.7,99.0,100.6$ & & \\
\hline
\end{tabular}

by the Centre for Drug Evaluation, China Food and Drug Administration.

LOD and LOQ. LOD and LOQ were determined to evaluate the sensitivity of the HPLC analysis. The LOD and LOQ for $\mathrm{CA}, \mathrm{CDCA}, \mathrm{CAME}$, and DCA were determined as signal-tonoise $(\mathrm{S} / \mathrm{N})$ ratios of 3 and 10 , respectively. To assess the precision of LOQ, six separate solutions at the minimum concentration were prepared, and the RSD values were calculated from peak areas of $\mathrm{CA}$ and related substances. The LOD and LOQ for CA and related substances were $0.60 \mu \mathrm{g} / \mathrm{mL}$ and $2.0 \mu \mathrm{g} / \mathrm{mL}$, respectively.

Solution stability. To assess the stability of standard and sample solutions, solutions were freshly prepared and left in the dark at ambient temperature or in a refrigerator at $2-10{ }^{\circ} \mathrm{C}$ for 1 day, 3 days, and 7 days. Compared with the initial assay, the difference in the CA assay for standard solutions at each time point should be less than $2 \%$. Compared with the freshly prepared sample solution, the difference in impurities detected for sample solutions at each time point should be not greater than $0.1 \%$.

The differences in standard solutions for 1 day, 3 days, and 7 days were $0.4 \%, 0.1 \%$, and $1.5 \%$, respectively, at room temperature, and $0.6 \%, 0.2 \%$, and $1.4 \%$ at $2-10{ }^{\circ} \mathrm{C}$. The differences in sample solutions for 1 day, 3 days, and 7 days were $0.03 \%, 0.05 \%$, and $0.02 \%$, respectively, at room temperature, and $0.04 \%, 0.03 \%$, and $0.02 \%$ at $2-10{ }^{\circ} \mathrm{C}$. The results indicate that the solutions are stable over a period of 7 days.

Robustness. To determine the robustness, five parameters were varied: different columns of the same type, column temperature $\left(25{ }^{\circ} \mathrm{C}\right.$ and $\left.35{ }^{\circ} \mathrm{C}\right)$, flow rate $(0.8 \mathrm{~mL} / \mathrm{min}$ and $1.2 \mathrm{~mL} / \mathrm{min}$ ), $\mathrm{pH}$ of dilute formic acid (2.3 and 2.7), and the percentage composition of mobile phase (MeCN-MeOH-diluted formic acid solution $=$ (1) 39:19:42, (2) 47:16:37, (3) 43:22:35, and (4) 43:12:45). The parameters of the initial conditions were set as the reference value. In all cases, the effects of the small changes applied to the method were evaluated by calculating the resolution factors and the differences in the impurity contents.

As reported in SST, the resolution values of robustness studies were always greater than 1.5 . The differences in specified impurity contents were not more than $0.04 \%$, and the differences in total impurities were not more than $0.09 \%$. The results show that the small variations in different columns of the same type, column temperature, $\mathrm{pH}$ of dilute formic acid, and the percentage composition of the mobile phase do not affect the robustness of the system.

Samples test. Four commercial samples of CA bulk drugs were analyzed to determine the related impurities (Table 6).

Table 6. Impurity contents of CA bulk drugs

\begin{tabular}{lcccc}
\hline Analyte & Sample A & Sample B & Sample C & Sample D \\
\hline CDCA & $0.18 \%$ & $0.08 \%$ & $0.12 \%$ & $0.63 \%$ \\
CAME & $0.08 \%$ & $0.17 \%$ & $0.08 \%$ & ND \\
DCA & $0.38 \%$ & $0.12 \%$ & $0.29 \%$ & $1.17 \%$ \\
Total impurities & $0.71 \%$ & $0.42 \%$ & $0.55 \%$ & $2.18 \%$ \\
$\quad$ ND, not detected. & & & & \\
\hline
\end{tabular}

CDCA, CAME, and DCA were detected in samples A, B, and C. CAME was not found in sample D, but other unspecified impurities were detected. There was no unspecified impurity interfering with $\mathrm{CA}$ and its related impurities, indicating that the method can be used for the determination for CA-related impurities.

\section{Conclusion}

In the present work, the quantitative determination of related impurities in CA bulk drugs has for the first time been investigated by HPLC with a refractive index detector. Forced degradation studies demonstrate a good separation of CA from its related impurities and unspecified impurities. The method was found to be selective, linear, accurate, precise, sensitive, and robust. This method does not require expensive instruments as HPLC-mass spectrometry (MS) and can be used for the quality control assay of cholic acid bulk drugs in medicinal industries.

Acknowledgments. This work was supported by Natural Science Foundation of Guangdong Province (No. 2016A030310441), Science Foundation for Young Teachers of Wuyi University (Nos. 2015zk03 and 2016td01), and Startup Foundation for Doctors of Wuyi University (2016BS18) for the financial support. The authors thank Dr. John S. Lomas for his help in correcting the English of this article.

\section{References}

1. Russell, D. W. Annu. Rev. Biochem. 2003, 72, 137-174.

2. Hofmann, A. F. Arch. Intern. Med. 1999, 159, 2647-2658.

3. Thomas, C.; Pellicciari, R. and Pruzanski, M. Nat. Rev. Drug Discov. 2008, 7, 678-693.

4. Hofmann, A. F.; Hagey, L. R. Cell. Mol. Life Sci. 2008, 65, 2461-2483.

5. Committee for Medicinal Products for Human Use of European Medicines Agency, Assessment report: Orphacol (cholic acid), 2013, http://www. ema.europa.eu/docs/en_GB/document_library/EPAR_-Public_assessment report/ human/001250/WC500131542.pdf (accessed Dec. 20016).

6. Lu, Q. H., China Patent CN101550176B, 2009.

7. Peepliwal, A.; Bonde, C. G. and Bothara, K. G. J. Pharmaceut. Biomed. 2011, 54, 845-849.

8. Suzuki, Y.; Kaneko, R. and Nomura, M. Nagoya J. Med. Sci. 2013, $75,57-71$.

9. Peng, C.; Tian, J. and Lv, M. J. Chromatogr. Sci. 2014, 52, 128-136.

10. Scalia, S.; Umberto, C. and Marco, F. Anal. Lett. 1994, 27, 1789-1804.

11. Perwaiz, S.; Tuchweber, B. and Mignault, D. J. Lipid Res. 2001, 42, $114-119$.

12. European Directorate for Quality Medicines, European Pharmacopoeia 7.0, 3180-3181.

13. ICH Harmonised Tripartite Guideline Q2 (R1), Validation of Analytical Procedures: Text and Methodology. http://www.ich.org/products/guidelines/ quality/article/quality-guidelines.html (accessed Dec. 2016).

14. Center for Drug Evaluation of China Food and Drug Administration, Technical Guideline for Analytical Method Validation on Chemical Drug Quality Control, http://www.cde.org.cn/zdyz.do?method=largePage\&id=2063 (accessed Dec. 2016).

15. Centre for Drug Evaluation of China Food and Drug Administration, Technical Guideline for Research on Chemical Drug Impurities, http://www. cde.org.cn/zdyz.do?method=largePage\&id=2060 (accessed Dec. 2016) 